\title{
Insulation systems for buildings and structures based on expanded polyethylene
}

\author{
Vyacheslav Semenov ${ }^{1}$, Sergey Kozlov ${ }^{1, *}$, Alexey Zhukov ${ }^{1}$, Karen Ter-Zakaryan ${ }^{2}$, Ekaterina \\ Zinovieva $^{1}$ and Ekaterina Fomina ${ }^{1}$ \\ ${ }^{1}$ Moscow State University of Civil Engineering, Yaroslavskoe shosse, 26, Moscow, 129337, Russia \\ ${ }^{2}$ TEPOFOL Ltd., Shcherbakovskaya str., 3, of. 606, Moscow, 105318
}

\begin{abstract}
Insulation systems for buildings and structures imply the use of efficient thermal insulation products based on mineral wool, expanded polystyrene, expanded polyurethane, etc. For a long time, products from non-cross-linked expanded polyethylene were used as insulation for pipelines, reflective insulation, protection against air infiltration, etc. Modern technologies and engineering solutions allowed widening the field of application of non-cross-linked expanded polyethylene (NXLPE) as a construction insulation material. In particular, we can consider a complex of insulation systems for walls, floors and a pitched roof, which allows to form a fully insulating shell of a low-rise building, e.g. a cottage. The novelty of the patented technology Tepofol ${ }^{\circledR}$ and that of the material concerned in comparison with the known solutions is the development of a rolled material based on NXLPE (20 to $150 \mathrm{~mm}$ thick) with a lock joint, as well as the technology of seamless connection of individual heat-insulating cloths. The rolls of NXLPE are mechanically fixed to the frame and connected with the lock. One of the advantages of expanded polyethylene, which only few insulating materials possess, is the possibility of forming seamless insulating shells. The article considers a number of insulation systems based on the use of products from expanded polyethylene. In particular, these are the systems of insulation of the walls of frame buildings, the insulation of floors, as well as the insulation of logistics facilities and hangars.
\end{abstract}

\section{Introduction}

The application of energy-efficient building insulation systems focuses on solving of four following groups of tasks. First, the energy saving (decrease of direct thermal losses) is meant to be provided. Secondly, the structures durability (protection of load-bearing structures against the dangerous thermal influence and moisture) should be provided for. Thirdly, comfortable indoor conditions are set to be arranged. In the fourth place, providing for the appropriate temperature and humidity conditions should be as well [1-4].

\footnotetext{
* Corresponding author: ser-31-16@mail.ru
} 
As practice shows, all these factors have a social and environmental focus. The main social factor is the creation of comfortable temperature and humidity conditions, the main environmental factor is the reduction of energy costs [5-8].

In the process of building system implementation, not only proper application of thermal insulation (the same as any other utilities though) is considered to be the most important task, but the minimization of thermal bridges or rather building up a seamless coating of insulated object is significant as well. This kind of seamless coatings can be implemented either by means of spray polyurethane foam, or by means of roll-expanded polyethylene [9-11].

The spray polyurethane foam is applicable only on solid surfaces (preferably on rigid bases). Besides, the application possibility depends on weather conditions: it is impossible to carry out the work at the temperature lower than $+5^{\circ} \mathrm{C}$ in particular. The insulation system durability depends mostly on polymer coating adhesion, and the realization of an efficient insulating layer is determined by the temperature and atmospheric conditions during the applying process. The applying process itself involves the additional safety requirements because of the components toxicity.

Taking all the special features of expanded polyethylene (low density and thermal conductivity, very low moisture and vapor permeability, high combustibility, high waterproofing qualities and sufficient strength characteristics) into consideration, the following implementation systems with this material have been developed: exterior insulation of facades, interior insulation of mansard roofs, interior insulation of framed and frameless garages, hangars and storage facilities as well as insulation of balconies and loggias or the element of floating floors [12-13].

\section{Problem statement}

The experimental research concerning the expanded polyethylene applicability in the insulation systems of framed and frameless storage premises and hangars has been performed in the National Research Moscow State University of Civil Engineering (MGSU) with participation of the TEPOFOL Ltd. The research of physical and mechanical properties of Tepofol ${ }^{\circledR}$ expanded polyethylene in exterior and interior insulation systems was carried out in the Research Institute of Construction Physics of Russian Academy of Architecture and Construction Sciences (NIISF RAASN) as well. The RF Patent No 2645190 «Lock technology of thermal insulation material for seamless welding of connecting locks», registered 16.02.2018, has been received.

The thermal insulating material based on Tepofol ${ }^{\circledR}$ non-cross-linked expanded polyethylene (NXLPE), as well as insulation systems with the usage of this material were considered as the subject matter of the research. The average density of the samples was 22 $\mathrm{kg} / \mathrm{m}^{3}$. The determination of geometrical characteristics of the samples, their mass as well as the average compression strength have been tested in accordance with Russian standard GOST 17177-94. The evaluation of compression creep of the NXLPE samples has been performed according to Russian standard GOST EN 1606-2011.

\section{Results}

The tests results showed that neither cladding of the products, nor climate effect does not practically exert any influence on the mechanical properties of the expanded polyethylene samples. The strength reduction for a foiled sample does not exceed $2.1 \%$, whereas that caused by the climate effect does not exceed $3.4 \%$ - these figures are below the value of statistical experimental error, which is equal to $4.9 \%$. 
On the contrary, the influence of the configuration factor $(\mathrm{S} / \mathrm{h})$ due to the sample compression deformation conditions and material structure is great (Fig. 1). Expanded polyethylene represents an elastic material with the high compressive strength. Pores of the expanded polyethylene are filled with gas, and the separate membrane cells are practically gas-impermeable.

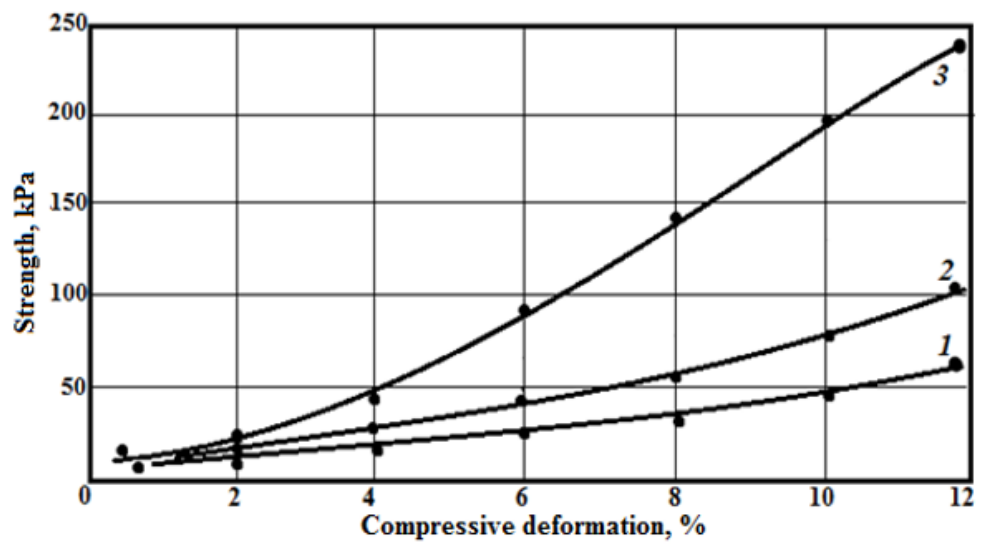

Fig. 1. Deformation curves of the NXLPE samples: 1 - samples with the dimensions of $100 \times 100 \times 100$ $\mathrm{mm} ; 2$ - samples with the dimensions of $100 \times 100 \times 50 \mathrm{~mm} ; 3$ - samples with the dimensions of $200 \times 200 \times 50 \mathrm{~mm}$

Analysis of the loads on thermal insulating layer shown, that the loads do not exceed 15 $\mathrm{kPa}$ and the deformation of the thermal insulating layer is $0 \ldots 1 \mathrm{~mm}$. Because the deformation of the floor thermal insulation is approximately $1 \%$ of its thickness, the increase of thermal conductivity of thermal insulating layer will not exceed $1 \%$. It means that nominal thermal conductivity of NXLPE in the floating floor construction will be $0.038 \times 1.01=0.039 \mathrm{~W} /(\mathrm{m} \cdot \mathrm{K})$. The low vapor permeability and high resistibility to the atmospheric effects should be regarded as an advantage of NXLPE. At the same time a high combustibility of foam plastic materials is their serious disadvantage [14, 15].

The results of acoustic tests concerning the floating floor construction on an reinforced concrete floor have been obtained, too. The performed measurements of dry screed floors impact noise level, which implied the including of roll expanded polyethylene of 10 and 20 $\mathrm{mm}$ thick in the capacity of a resilient layer, showed the decrease of impact noise level by 24 and $26 \mathrm{~dB}$, respectively.

The minimization of cold bridges (exclusion of thermal losses over the smooth insulating coating surface) provides for significant advantages to the NXLPE products in comparison with the traditional plate or roll materials. The point is that even in case of twolayer insulation with overlapping (by means of two planar coordinates shift), it is impossible to avoid the development of cold bridges.

\section{Discussion}

Seamless insulation of the structures with the application of roll material Tepofol ${ }^{\circledR}$ with heat-reflecting coating provides for an efficient insulation system thanks to the development of an integrated hermetical envelope of the building. This effect can be achieved by means of thermal welding of the locking joints, which are placed at the rolls junctions. As a result of the process of such monolithic insulation, it is possible to obtain the seamless insulating coating, which does not have thermal bridges over the smooth 
surface and prevents from the indoor moisture penetration. In this case, the efficiency of thermal insulating skin significantly increases, the interior temperature stays at the present level and the costs for internal heating reduce. This method as well as the thermal insulating material itself has been developed by TEPOFOL Ltd.

The framing system with peripheral insulation is meant to be used within the scope of cottages insulation (Fig. 2). It is recommended to use the wooden products saturated with fire-retardant and antiseptic agents as a frame. The NXLPE rolls Tepofol® (the roll of any length can be manufactured in conformity with technical requirements) are reeled out along the perimeter of the building and fixed to the timber posts by means of headed screws.

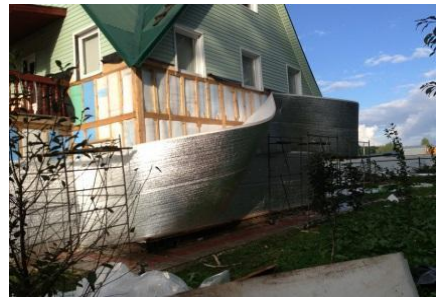

a

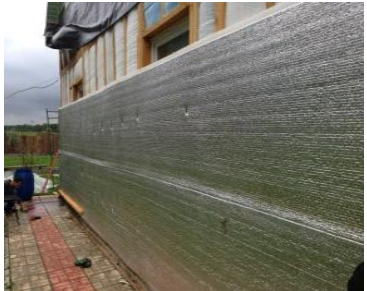

b

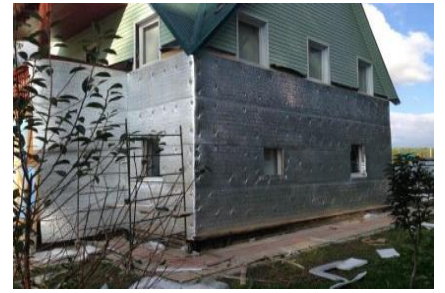

c

Fig. 2. Thermal insulation of the cottage: $a$ - unreeling of the NXLPE roll; $b$ - fixing of the thermal insulation and crosslinking of the NXLPE roll; $\mathrm{c}$ - arrangement of an insulating periphery and window apertures

Seamless insulation of hangar vegetable storehouses with the application of roll material Tepofol ${ }^{\circledR}$ with heat-reflecting coating provides for an efficient insulation system of vegetable storage thanks to the development of an integrated hermetical envelope of the building (Fig. 3).
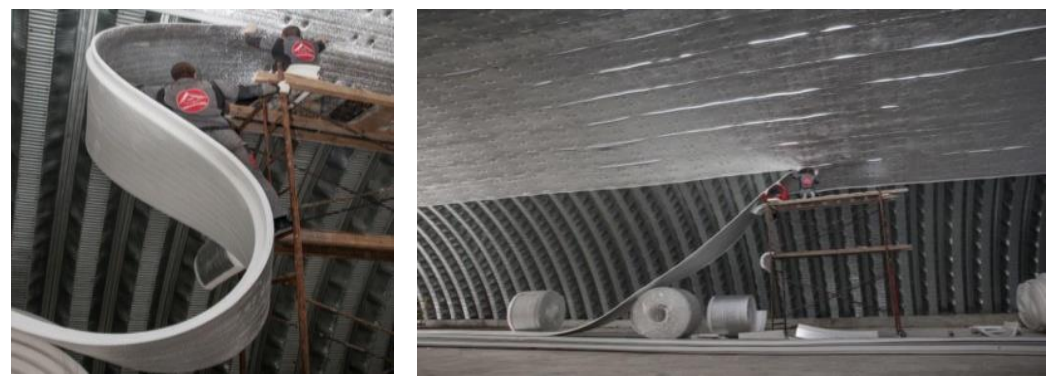

Fig. 3. Installation of insulation coating of a hangar

Another, not less interesting for a builder field of NXLPE application is "floating floors" in which expanded polyethylene performs the function of both heat and sound insulation $[7,8]$. The resulting single insulating cloth is sealed, that is, there are no gaps or joints in it, which prevents the heat losses. This approach to the thermal insulation ensures the preservation of heat inside the building and, considerably improves the energy-saving properties of the insulation system and prevents the infiltration of steam and the formation of acoustic bridges $[9,10]$.

When warming the wooden floor, the stacking of the rolled thermal Tefofol insulation is recommended to be carried out throughout the whole floor area on lags (Fig. 4). The locking systems at the junction of two rolls are welded to each other in such a way that a sealed heat-insulating cloth is obtained. At the same time, the thermal insulation sheet is tightly fixed to the base along the entire perimeter. 


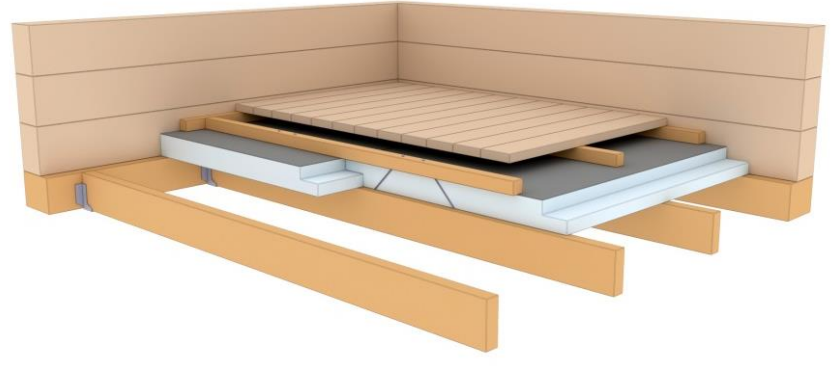

Fig. 4. The lagging floor with inclined fixing tapping screws
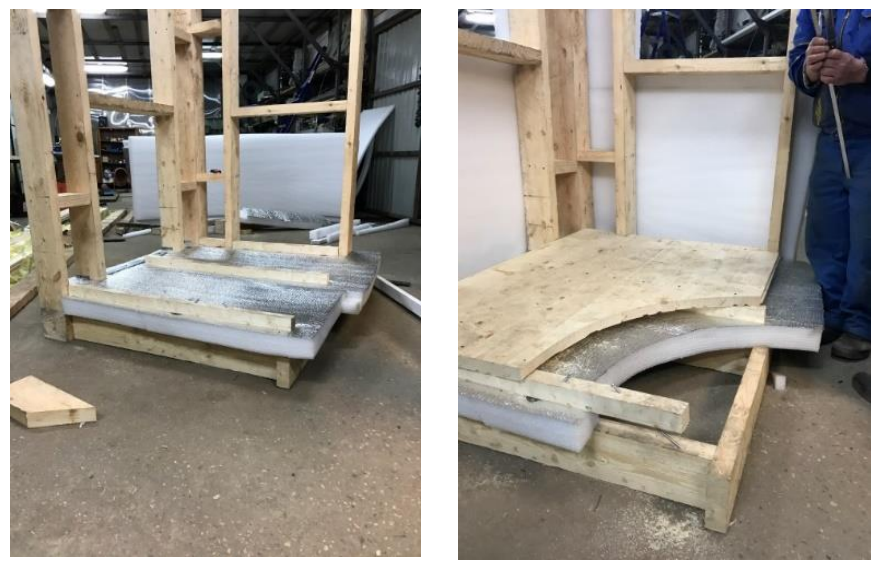

Fig. 5. Wooden floor insulation system

As a result of the special way of fixing the insulation to the lags, a girder is formed, through which the load from the floor is uniformly redistributed from the heater to the wooden bars and bolts. Then the finish coating (floorboard) is installed on the wooden bars. Due to the bars between the floorboard and the heat-insulating layer, there remains an air gap, which increases the thermal protection properties of the structure and helps to reduce the heat losses of the building as a whole. Consequently, the air gap functions as a heat insulator.

\section{Conclusions}

The application of the seamless junction technology with the usage of hot air welding allows the development of a seamless insulating blanket that consequently allows excluding an additional vapor barrier and windproof layer out of the structure. The RF Patent No 2645190 «Lock technology of thermal insulation material for seamless welding of connecting locks», registered 16.02.2018, has been received.

Thermal and energy efficiency of the insulating envelope accomplished by means of NXLPE rolls significantly increases with the application of the material with the heatreflecting layer. Herewith, the metallized coating is placed inside the insulated space and the insulant itself is fixed directly to the load-bearing frame.

The technology is implemented within the scope of insulation systems of framed cottages facades, framed and frameless storage facilities, hangars and storehouses and within the dry screed floating floor systems as well. 


\section{References}

1. P. Zhuk, A. Zhukov, Ecol. and ind. of Rus., 4, 52 (2018)

2. D. Novitckii, M. Romanovich, D. Makhov, MATEC Web of Conf., 170, 03002 (2018)

3. O. Novikova, S. Shirokova, A.Tabakova, A. Shadrin, MATEC Web of Conf., 170, 03006 (2018)

4. A. Aksenov, MATEC Web of Conf., 170, 03012 (2018)

5. I. Gnip, V. Keršulis, S.Vaitkus, Mech. of Comp. Mat., 4, 357 (2018)

6. I. Gnip, V.Keršulis, S.Vaitkus, Constr. Mat., 12, 40 (2018)

7. A. Zhukov, V. Semenov, I. Gnip, S. Vaitkus, MATEC Web of Conf., 117, 00184 (2017)

8. V. Semenov, A. Gubskiy, Izv. Vys. Uch. Zav., Ser. Tekn. Tekst. Prom., 3, 109 (2017)

9. V. Semenov, T. Rozovskaya, A. Gubskiy, Build. Mat., 6, 21 (2016)

10. A. Lepeshev, V. Kuimov, O. Sidorkina, A. Kozlov, T.Pogrebnaya, MATEC Web of Conf., 170, 04006 (2018)

11. S. Shmelev, Build. Mat., 3, 7 (2013)

12. N. Umnyakova, V. Tsygankov, V. Kuzmin, Hous. Constr., 1-2, 38 (2018)

13. A. Zhukov, K. Ter-Zakaryan, A. Zayafarov, Ye. Petrovsky, D.Tuchaev, Roof. and Ins. Mat., 6, 27 (2017)

14. A. Zhukov, K. Ter-Zakaryan, D. Tuchaev, E. Petrovskij, Int. Agr. J., 1 (361), 65 (2018) 